\title{
Deoxynivalenol Exposure Suppresses Adipogenesis by Inhibiting the Expression of Peroxisome Proliferator-Activated Receptor Gamma 2 (PPAR $\gamma 2$ ) in 3T3-L1 Cells
}

\author{
Yurong Zhao ${ }^{1,2}$, Shulin Tang ${ }^{1,2}$, Ruqin Lin ${ }^{1,2}$, Ting Zheng ${ }^{1,2}$, Danyang Li ${ }^{1,2}$, Xiaoxuan Chen ${ }^{1,2}$, \\ Jiahui Zhu ${ }^{1,2}$, Jikai Wen ${ }^{1,2, *}$ and Yiqun Deng ${ }^{1,2, * \mathbb{D}}$ \\ 1 Guangdong Provincial Key Laboratory of Protein Function and Regulation in Agricultural Organisms, \\ College of Life Sciences, South China Agricultural University, Guangzhou 510642, China; \\ 20171003017@stu.scau.edu.cn (Y.Z.); shulintang@scau.edu.cn (S.T.); linruqin@stu.scau.edu.cn (R.L.); \\ zhengting@stu.scau.edu.cn (T.Z.); lidanyang@stu.scau.edu.cn (D.L.); xuanzi@scau.edu.cn (X.C.); \\ jhz@stu.scau.edu.cn (J.Z.) \\ 2 Key Laboratory of Zoonosis of Ministry of Agriculture and Rural Affairs, \\ South China Agricultural University, Guangzhou 510642, China \\ * Correspondence: jkwen@scau.edu.cn (J.W.); yqdeng@scau.edu.cn (Y.D.); Tel.: +86-20-85201331 (J.W.); \\ +86-20-38294890 (Y.D.); Fax: +86-20-38604967 (J.W.); +86-20-38604967 (Y.D.)
}

Received: 3 July 2020; Accepted: 29 August 2020; Published: 31 August 2020

\begin{abstract}
Deoxynivalenol (DON) - a type B trichothecene mycotoxin, mainly produced by the secondary metabolism of Fusarium - has toxic effects on animals and humans. Although DON's toxicity in many organs including the adrenal glands, thymus, stomach, spleen, and colon has been addressed, its effects on adipocytes have not been investigated. In this study, 3T3-L1 cells were chosen as the cell model and treated with less toxic doses of DON (100 ng/mL) for 7 days. An inhibition of adipogenesis and decrease in triglycerides (TGs) were observed. DON exposure significantly downregulated the expression of $\operatorname{PPAR} \gamma 2$ and $\mathrm{C} / \mathrm{EBP} \alpha$, along with that of other adipogenic marker genes in 3T3-L1 cells and BALB/c mice. The anti-adipogenesis effect of DON and the downregulation of the expression of adipogenic marker genes were effectively reversed by PPAR $\gamma 2$ overexpression. The repression of PPAR $\gamma 2$ 's expression is the pivotal event during DON exposure regarding adipogenesis. DON exposure specifically decreased the di-/trimethylation levels of Histone 3 at lysine 4 in 3T3-L1 cells, therefore weakening the enrichment of H3K4me2 and H3K4me3 at the Ppar 2 promoter and suppressing its expression. Conclusively, DON exposure inhibited PPAR $\gamma 2$ expression via decreasing H3K4 methylation, downregulated the expression of PPAR $\gamma 2$-regulated adipogenic marker genes, and consequently suppressed the intermediate and late stages of adipogenesis. Our results broaden the current understanding of DON's toxic effects and provide a reference for addressing the toxicological mechanism of DON's interference with lipid homeostasis.
\end{abstract}

Keywords: deoxynivalenol; peroxisome proliferator-activated receptor gamma 2; adipogenesis; toxicology; histone modifications

\section{Introduction}

Deoxynivalenol (DON), a type B trichothecene mycotoxin, is one of the most polluting mycotoxins, and is mainly produced by Fusarium [1,2]. DON, also known as "vomitoxin", causes vomiting in swine [3]. DON has a negative impact on animal health, especially causing gastrointestinal disorders in monogastric animals [4]. Acute exposure to DON leads to vomiting and diarrhea, and is associated 
with a loss of appetite, while long-term exposure leads to decreased weight gain, intestinal toxicity, cell-mediated immune dysregulation, neurological disorders, lipid peroxidation, and high sensitivity towards disease [5-8]. The decrease in weight gain caused by DON still remains to be clarified. It is reasonable to consider that a lower intake of food in DON-exposed animal individuals would result in decreased weight gain due to diarrhea and loss of appetite, but it would be interesting to understand whether DON administration could directly inhibit adipogenesis.

Adipogenesis, the differentiation of preadipocytes, is a multi-step process involving the activation of transcription factors and the upregulation of adipocyte-specific genes, which lead to their differentiation to mature adipocytes [9-12]. Adipogenesis is mainly controlled by two protein families, CCAAT/enhancer-binding proteins (C/EBPs) and peroxisome proliferator-activated receptors (PPARs) [13-16]. Among these, C/EBP $\alpha$ and PPAR $\gamma$ function as key transcription factors, activating the expressions of a series of adipocyte-specific genes during terminal adipocyte differentiation.

C/EBP proteins are a family of basic region leucine zipper (bZIP) transcription factors that includes six members with related sequences and functions $(\alpha, \beta, \gamma, \delta, \varepsilon$, and $\zeta)$ [17]. C/EBP $\alpha$ is required for the proper control of adipogenesis, glucose metabolism, granulocytic differentiation, and lung development [18]. C/EBP $\alpha$ is induced during late adipogenesis and is most abundant in mature adipocytes, mediating growth arrest and terminal differentiation in concert with PPAR $\gamma$ [19].

PPARs are identified as members of the nuclear receptor superfamily of transcription factors, consisting of three isotypes-PPAR $\alpha, \operatorname{PPAR} \beta / \delta$, and PPAR $\gamma$-distributed in different tissues. PPAR $\gamma$ have two isoforms differing at the amino terminal extension with an extra thirty amino acids in PPAR $\gamma 2$ but not in PPAR $\gamma 1$. PPAR $\gamma 1$ is expressed in multiple tissues, but PPAR $\gamma 2$ is mainly expressed in adipose tissue and strongly upregulated during adipogenesis, suggesting a specific role in adipogenesis. Exogenous PPAR $\gamma 2$ but not PPAR $\gamma 1$ reactivates adipogenesis in PPAR $\gamma$-knockdown cells [20-23]. Recent studies have shown that histone modifications are important in regulating the expression of PPAR $\gamma$, mainly via methylation and acetylation at different amino acids of Histone 3-including H3K4me2/3, H3K9ac, and H3K27ac—associated with transcriptional initiation, "open" chromatin, and cis-regulator activity in the Ppar $\gamma$ promoter locus $[24,25]$. The activity of PPAR $\gamma$ is also regulated by its interaction with other nuclear proteins such as the co-activators [26]. These protein interactions are involved in the expression regulation of adipocyte genes, including fatty acid synthesis acetyl-CoA carboxylase alpha (ACACA), fatty acid synthase (FASN), fatty acid binding protein 4 (FABP4), and fatty acid translocase (CD36), which participate in different adipogenic functions, such as fatty acid synthesis, fatty acid transport, and energy metabolism [27]. ACACA catalyzes the carboxylation of acetyl CoA to form malonyl-CoA, the first committed step in the synthesis of long-chain fatty acids [28]. FASN is a multifunctional enzyme involved in lipogenesis, the synthesis of long-chain fatty acids from acetyl-CoA, and promoting the cytoplasmic storage of triglycerides [11]. FABP4, originally named adipocyte protein 2 [29], is the first identified PPAR $\gamma 2$ target gene and functions in fatty acid transport, facilitating the cellular uptake of long-chain fatty acids for metabolic processing or storage [30]. CD36 was reported to play a significant role in adipocyte cholesterol and adipogenesis metabolism [31,32].

In the present study, the effects of DON exposure on adipogenesis were evaluated for the first time. Our results demonstrated that DON inhibited the expression of adipogenic marker genes, thereby suppressing adipogenesis both in vitro and in vivo. PPAR $\gamma 2$ overexpression rescued the inhibitory effect of DON on lipid accumulation and the expression of adipogenesis marker genes in 3T3-L1 cells. Furthermore, we revealed that it repressed PPAR $\gamma 2$ expression by reducing H3K4me2 and H3K4me3 enrichment at the promoter of Ppar 2 2. Our findings suggested that DON suppressed adipogenesis by inhibiting PPAR $\gamma 2$ expression. The elucidation of its toxicological actions in adipogenesis will provide a theoretical reference for the subsequent exploration of its effects on lipid homeostasis and new insights into its suppression of weight gain. 


\section{Results}

\subsection{DON Suppresses Intracellular Lipid Accumulation in 3T3-L1 Cells}

3T3-L1 is a well-established cell line commonly used to study adipogenesis in vitro [33]. DON cytotoxicity was measured in 3T3-L1 cells by a CCK-8 assay. The cells were incubated with various concentrations of DON (50-800 ng/mL) for 1, 2, 3, or $7 \mathrm{~d}$ (Figure 1a). DON administration to 3T3-L1 cells at 50 and $100 \mathrm{ng} / \mathrm{mL}$ had little effect on cell proliferation, and that at $200 \mathrm{ng} / \mathrm{mL}$ caused less than $10 \%$ cell death at all treatment times. However, a more obvious decrease in cell viability was observed upon treatment with 400 and $800 \mathrm{ng} / \mathrm{mL}$ DON exposure, suggesting that its cytotoxicity was dose dependent. To minimize the toxicity of DON in the cells, we determined $100 \mathrm{ng} / \mathrm{mL}$ as the optimal maximal concentration in 3T3-L1 cells. 3T3-L1 preadipocytes were induced to differentiate into mature adipocytes and then treated with 100 and $200 \mathrm{ng} / \mathrm{mL}$ DON for 7 days. To investigate the effects of DON on intracellular lipid accumulation, the number of lipid droplets in adipocytes was determined by Oil Red O staining. The number of lipid droplets was clearly decreased in DON-induced cells compared to controls (Figure 1b,c). In addition, cells treated with 100 and $200 \mathrm{ng} / \mathrm{mL}$ DON displayed significant decreases in the basal levels of triglycerides (0.65- and 0.57-fold, respectively) (Figure 1d). DON had a dose-dependent, negative effect on both lipid droplets and TG levels. These data suggested that DON inhibited adipogenesis and had an apparent negative impact on 3T3-L1 adipocytes, even at relatively non-toxic concentrations. 
a
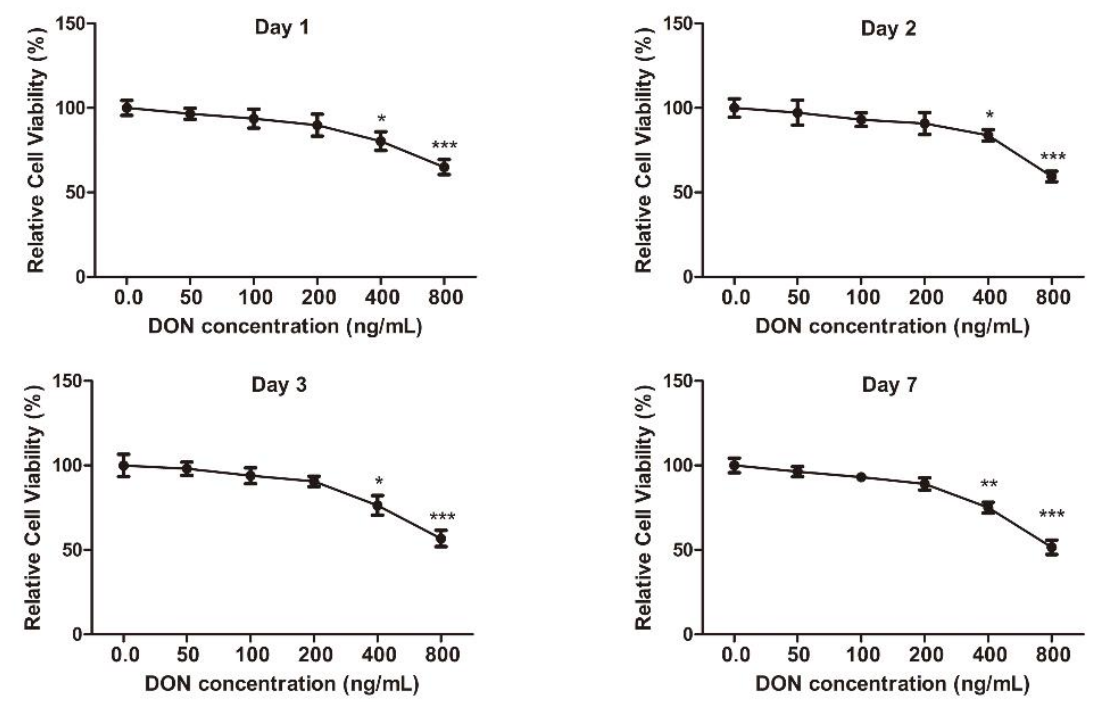

b

Ctrl

DON $100 \mathrm{ng} / \mathrm{mL}$

DON $200 \mathrm{ng} / \mathrm{mL}$
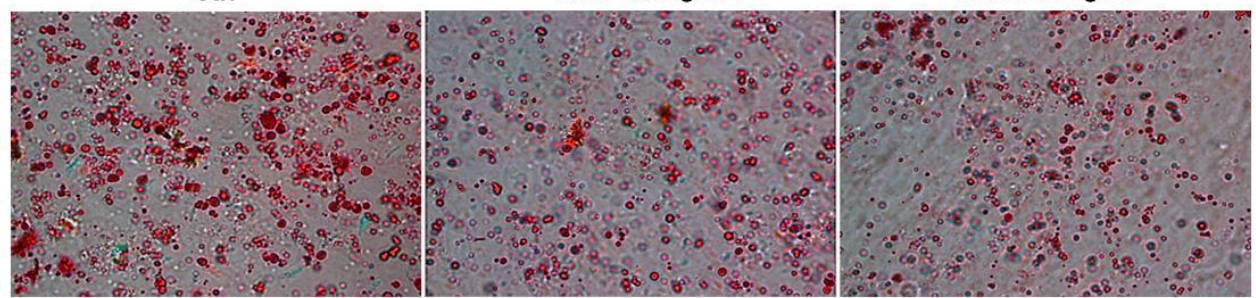

C

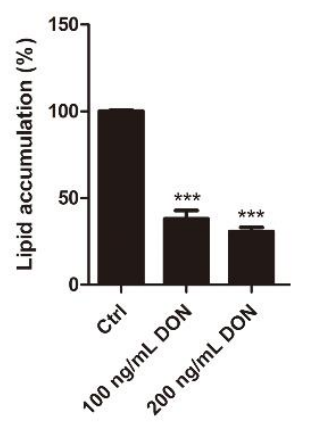

d

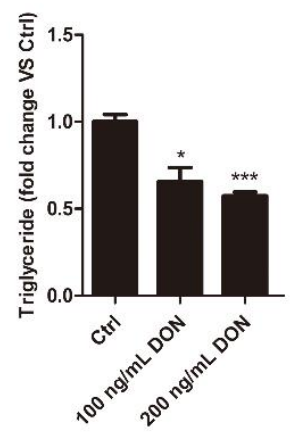

Figure 1. Effect of DON on adipogenesis in 3T3-L1 cells. (a) Cytotoxicity of DON in 3T3-L1 cells. The effect of DON on metabolic activity was examined by the CCK-8 assay. 3T3-L1 preadipocytes were treated with $0,50,100,200,400$, or $800 \mathrm{ng} / \mathrm{mL}$ DON for 1, 2, 3, or $7 \mathrm{~d}$, respectively. The values are expressed as percentages of control responses and were obtained from three independent experiments with six replications. (b) Lipid accumulation was visualized and quantified by Oil Red O staining. The cells were photographed at $\times 100$ magnification, and morphological changes were assessed based on lipid accumulation with or without DON (100 and $200 \mathrm{ng} / \mathrm{mL}$ ) on Day 7. (c) 3T3-L1 cells were treated with isopropanol, and lipid accumulation was measured according to the absorbance at 510 $\mathrm{nm}$. Lipid accumulation in the control group cells was compared to that in the DON-induced cells. (d) DON inhibited TG accumulation in 3T3-L1 cells. 3T3-L1 preadipocytes were cultured in DMEM + FBS medium containing the differentiation cocktail, with or without DON (100 and $200 \mathrm{ng} / \mathrm{mL}$ ) for 7 days. The results are representative of three independent experiments, and statistical significance is indicated by ${ }^{*} p<0.05,{ }^{* *} p<0.01,{ }^{* * *} p<0.001$.

\subsection{Low Expression Levels of Adipogenic Marker Genes in Differentiated 3T3-L1 Cells Treated with DON}

Highly expressed during adipogenesis, $\mathrm{C} / \mathrm{EBP} \alpha$ and PPAR $\gamma 2$ coordinately regulate each other and play critical roles in the regulation of adipocyte phenotypes, as well as triglyceride accumulation [34]. 
To understand the molecular mechanisms underlying the DON-induced inhibition of adipogenesis, the expression of genes involved in control of adipogenesis were assessed in 3T3-L1 cells. Treatment with $100 \mathrm{ng} / \mathrm{mL}$ DON substantially decreased the mRNA and protein levels of C/EBP $\alpha$ and PPAR $\gamma 2 \mathrm{vs}$. control (Figure 2a,b), implying that DON exposure affected adipogenesis by inhibiting the expression of two master regulators. The expression of other adipogenic marker genes was examined. As expected, the expression of two lipogenic enzymes, FASN and ACACA, and the fatty acid transport proteins, FABP4 and CD36, was significantly downregulated at both the mRNA and protein levels by DON administration. (Figure 2c,d). However, the expression of early adipogenic factors such as C/EBP $\beta$ and $\mathrm{C} / \mathrm{EBP} \delta$, which regulate PPAR $\gamma 2$ expression, were not apparently affected by DON administration (Figure S1a,b). This suggested that DON exposure might affect adipogenesis by targeting the control of PPAR $\gamma 2$ expression.

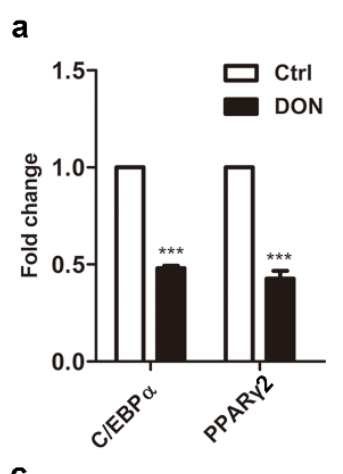

C

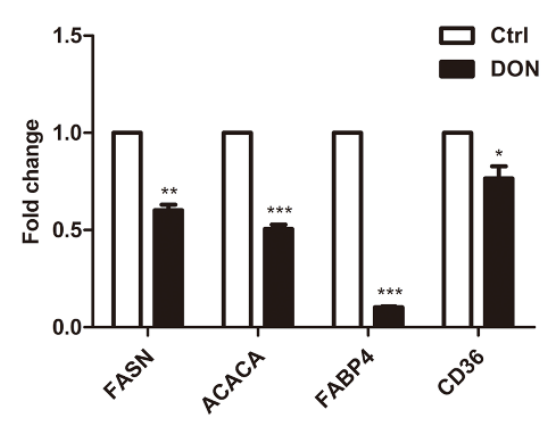

b
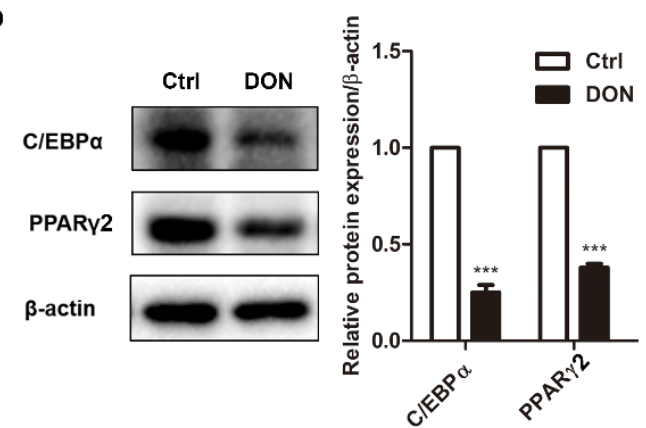

d

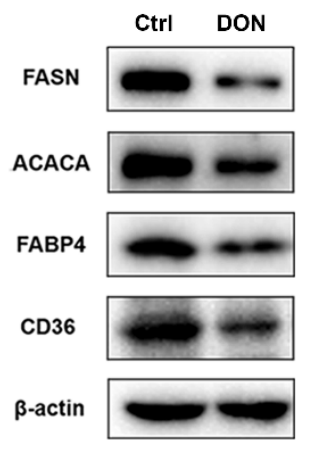

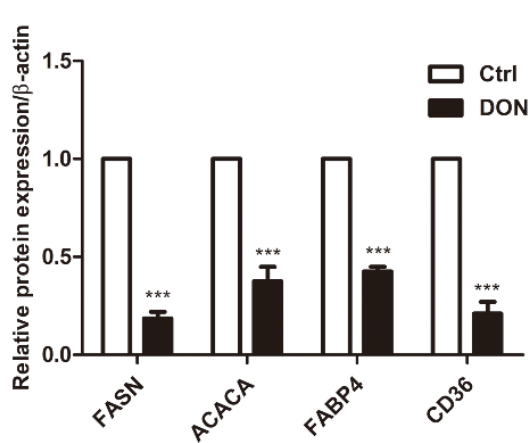

Figure 2. The effect of DON on the expression of adipogenic marker genes in 3T3-L1 cells. 3T3-L1 adipocytes were treated with $100 \mathrm{ng} / \mathrm{mL}$ DON during differentiation. The cells were harvested at the end of a 7-day differentiation. The expression of adipogenic marker genes was quantified by RT-PCR and Western blotting. (a,c) C/ebpo, Ppary2, Fasn, Acaca, Fabp4, and Cd36 mRNA levels in 3T3-L1 cells. (b,d) C/EBP $\alpha$, PPAR $\gamma 2$, FASN, ACACA, FABP4, and CD36 protein levels in 3T3-L1 cells (left). Quantification of protein levels (right). The results are representative of three independent experiments, and statistical significance is indicated by ${ }^{*} p<0.05,{ }^{* *} p<0.01,{ }^{* * *} p<0.001$.

\subsection{Overexpression of PPAR 22 Attenuated DON-Induced Inhibition of Adipogenesis}

PPAR $\gamma 2$ is the most important inducer of adipogenesis, and its expression in 3T3-L1 cells is strongly inhibited by DON. To verify whether the PPAR $\gamma 2$ pathway governed adipogenesis in DON-induced adipocytes, PPAR $\gamma 2$ was overexpressed in 3T3-L1 cells (Figure S2). As shown in Figure 3a,b, PPAR $\gamma 2$ overexpression significantly increased the number of lipid droplets and reduced the inhibitory effect of DON on the number of lipid droplets. A similar but less pronounced result was observed in cells treated with $1 \mu \mathrm{M}$ rosiglitazone (RGZ), a PPAR $\gamma$ agonist (Figure 3a,b). PPAR $\gamma 2$ overexpression antagonized the DON-induced reduction of TG levels, slightly better than RGZ (Figure 3c). These results further indicated that DON downregulated PPAR $\gamma 2$ at the protein level, and even RGZ agonism was unable to fully restore its functions in DON-treated cells. Therefore, DON-induced downregulation of PPAR $\gamma 2$ prevented adipogenesis and the accumulation of lipid droplets during 3T3-L1 cell differentiation. 
a
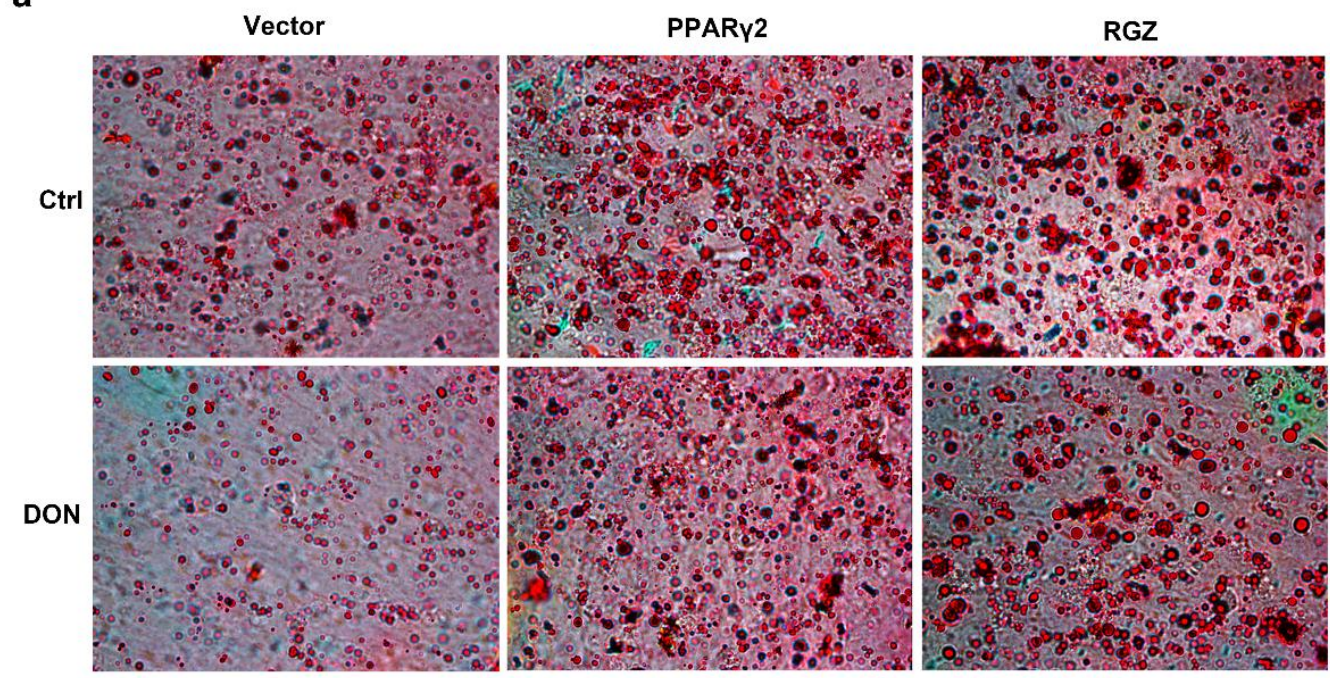

b

C
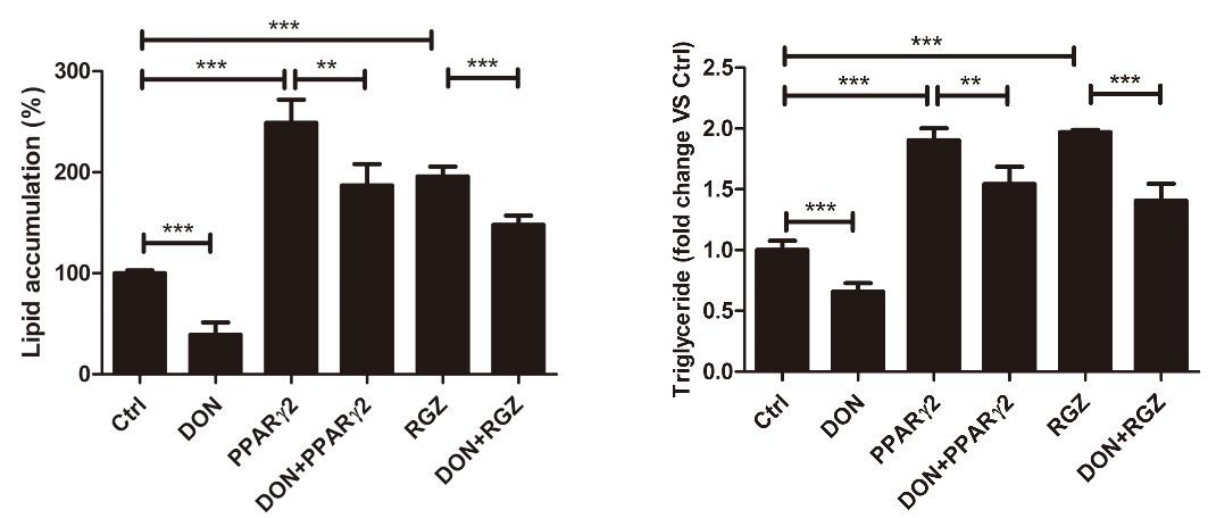

Figure 3. PPAR $\gamma 2$ overexpression attenuated the DON-induced inhibition of adipogenesis in 3T3-L1 cells. 3T3-L1 preadipocytes were transfected with PPAR $\gamma 2$ or treated with RGZ $(1 \mu \mathrm{M})$ and then cultured in DMEM + FBS medium containing the differentiation cocktail with or without DON $(100 \mathrm{ng} / \mathrm{mL})$ for 7 days. (a) Oil Red $O$ staining. The cells were photographed at $\times 100$ magnification. (b) Quantification of lipid accumulation. (c) TG levels. The results are representative of three independent experiments, and statistical significance is indicated by ${ }^{* *} p<0.01,{ }^{* * *} p<0.001$.

\subsection{Overexpression of PPAR 2 Attenuated DON-Induced Downregulation of Adipogenic Marker Genes}

We investigated whether the expression of other adipogenic marker genes controlled by PPAR $\gamma 2$ and downregulated by DON treatment was restored in PPAR $\gamma 2$-overexpressing cells. PPAR $\gamma 2$ overexpression significantly upregulated the mRNA levels of the adipogenic marker genes C/ebp $\alpha$, Fasn, Acaca, Fabp4, and Cd36. The inhibitory effect of DON on these genes was apparently abrogated (Figure 4a). PPAR $\gamma 2$ overexpression also restored the expression of FASN and ACACA at the protein level in DON-induced 3T3-L1 adipocytes (Figure 4b,c). These results suggested that the DON-induced inhibition of adipogenic marker genes was counteracted by PPAR $\gamma 2$ overexpression, showing that the PPAR $\gamma 2$ pathway played a crucial role in the DON-induced inhibition of adipogenesis. 
a
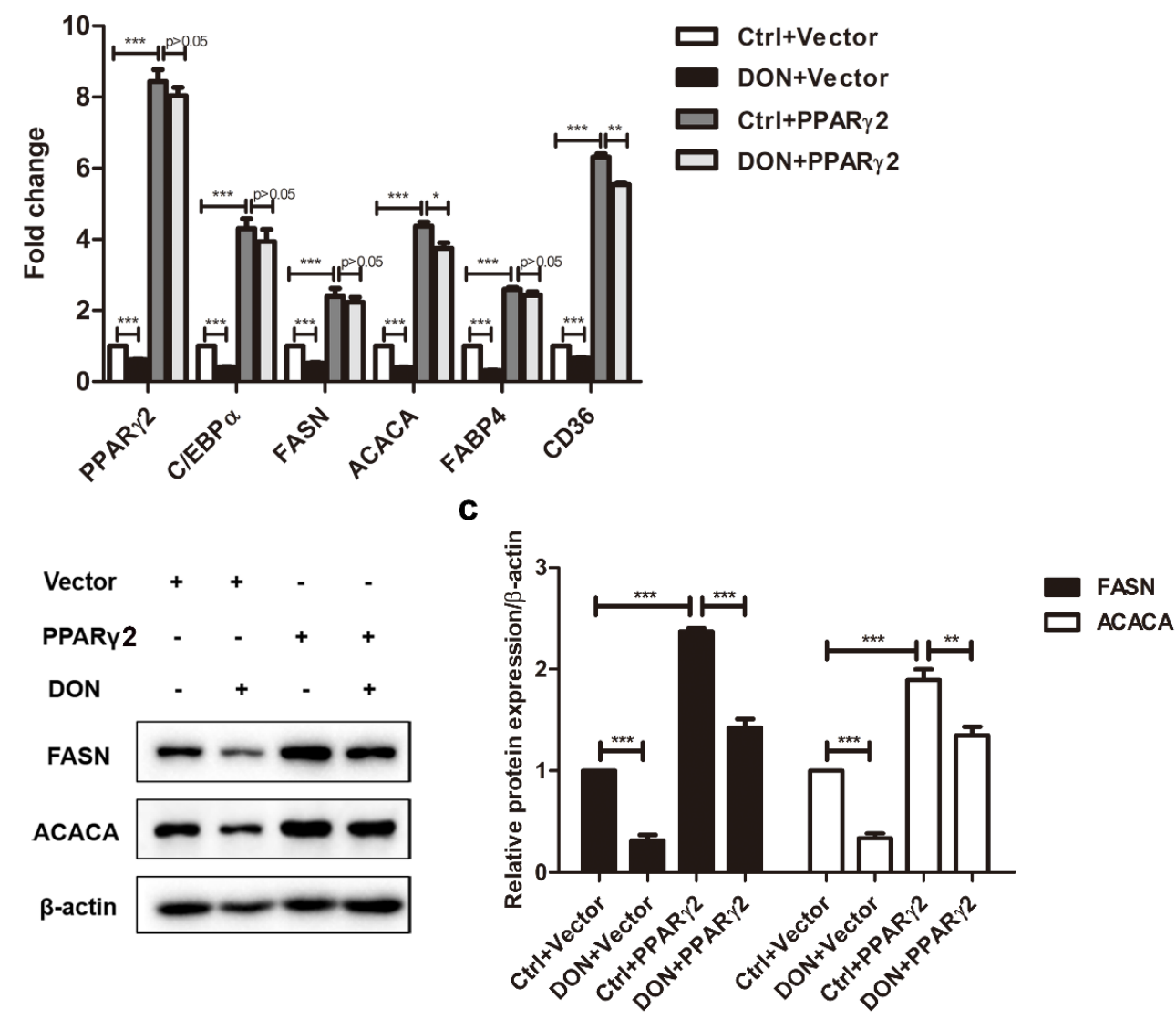

Figure 4. DON-induced downregulation of adipogenic marker genes was reversed by PPAR 2 overexpression in 3T3-L1 cells. Adipocyte cells were transfected with PPAR $\gamma 2$ or empty vector and treated with or without $100 \mathrm{ng} / \mathrm{mL}$ DON during differentiation. Total RNA or protein was isolated at the end of a 7-day differentiation. RT-PCR and Western blot analyses confirmed the expression of adipogenic marker genes. (a) C/ebpo, Ppary2, Fasn, Acaca, Fabp4, and Cd36 mRNA levels in 3T3-L1 cells. (b) FASN and ACACA protein levels in 3T3-L1 cells. (c) Quantification of protein levels. The DON, PPAR $\gamma 2$ overexpression, and DON + PPAR $\gamma 2$ overexpression groups normalized by the control group. The results are representative of three independent experiments, and statistical significance is indicated by ${ }^{*} p<0.05,{ }^{* *} p<0.01,{ }^{* * *} p<0.001$.

\subsection{DON Decreases WAT Size and TG Levels in BALB/c Mice}

To further confirm the effect of DON on adipogenesis in vivo, the body weights of mice were measured weekly for 28 days. Decreased body weight gain was observed after Day 21 in DON-induced mice and was most obvious on Day 28, compared to the control group (Figure S3a). The mice were sacrificed on Day 28, and then, their epididymal white adipose tissue (eWAT) and perirenal white adipose tissue (pWAT) were examined, showing a drastically reduced volume after DON administration (Figure 5a,b). DON exposure markedly reduced epididymal and perirenal fat mass $(10.11 \%$ and $20.43 \%)$ compared to those of the control group (Figure 5c). Histological analysis of the adipocyte tissue showed that, in DON-induced mice, the size of cells in the epididymal and perirenal adipose tissues was significantly decreased compared to that of those of the control mice (Figure 5d). DON exposure also reduced the epididymal and perirenal fat cell numbers compared to those in the control group (Figure 5e). The triglyceride content, reflecting the extent of lipid storage, was also decreased in the DON-induced animals (Figure 5f). We next determined that the mRNA levels of caspase 3 and caspase 9 were upregulated by DON treatment in the mice's livers and kidneys, suggesting that DON not only inhibited adipogenesis in mouse adipose but also caused the apoptosis of mouse livers and kidneys (Figure S3b). 


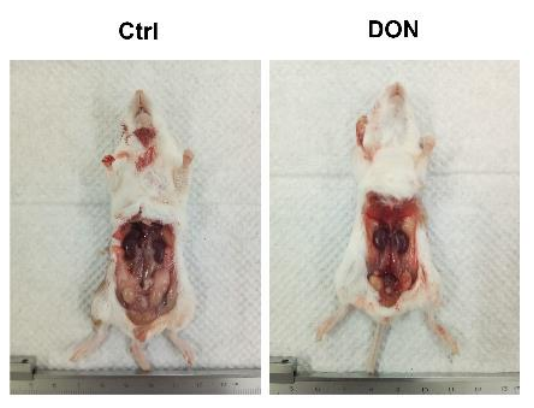

d

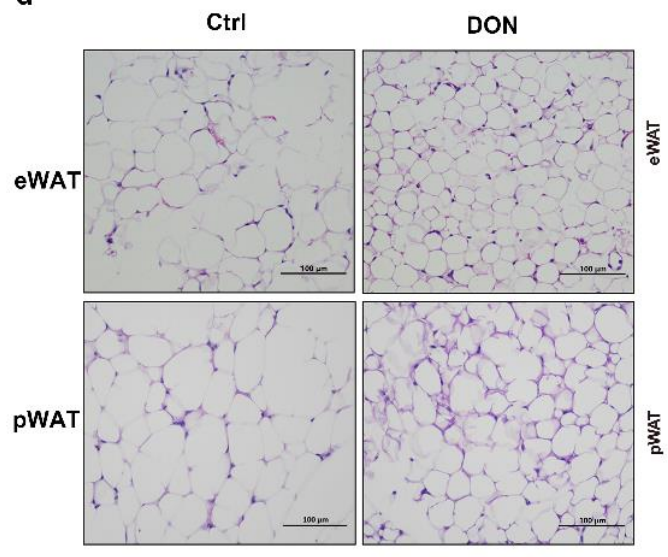

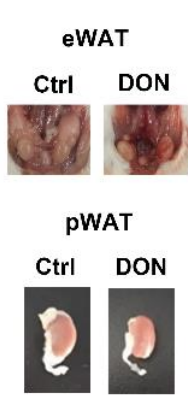

C

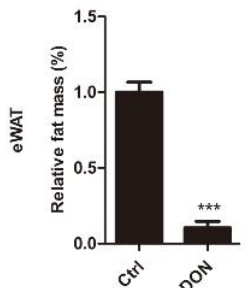

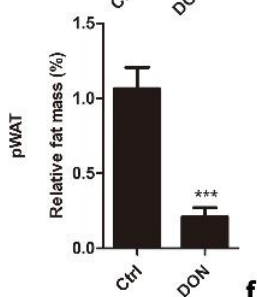

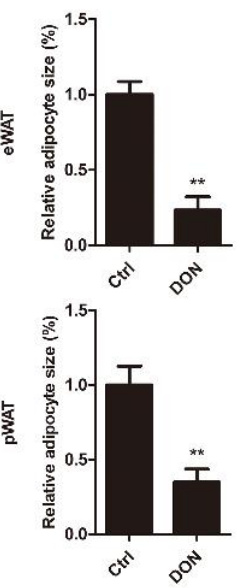

率

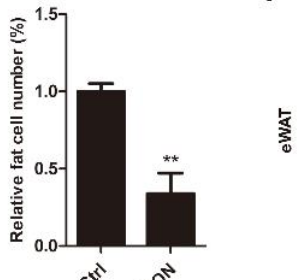

害

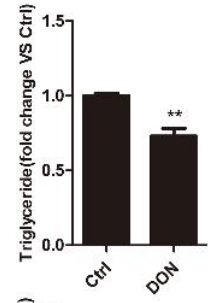

率

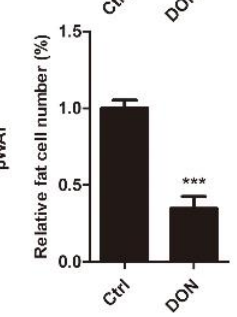

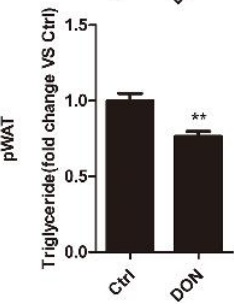

Figure 5. The effect of DON on adipogenesis in mice. Five-week-old SPF male BALB/c mice were randomized into two groups ( $n=5 /$ group) — control group and DON group ( $3 \mathrm{mg} / \mathrm{kg} / \mathrm{day})$-for four weeks. (a) Representative pictures of mice. (b) The volume of epididymal eWAT and pWAT. (c) The weights of eWAT and pWAT in DON-induced mice compared to those in the control mice. (d) Histological analysis of eWAT and pWAT after staining with hematoxylin and eosin (H\&E), followed by microscopic analysis. Scale bar is $100 \mu \mathrm{m}$ (left). Average cell size in DON-induced mice compared to that in the control group (right). (e) The relative cell numbers of eWAT and pWAT in DON-induced mice compared to those in the control mice. (f) The TG level in DON-induced mice compared to that in the control group. Data are presented as means $\pm \mathrm{SD}, n=5$. The results are representative of three independent experiments, and statistical significance is indicated by ${ }^{* *} p<0.01$, ${ }^{* *} p<0.001$.

\subsection{Low Expression Levels of Adipogenic Marker Genes in Mice Treated with DON}

The DON exposure inhibited adipogenesis in the mice, consistent with the result in 3T3-L1 cells. It could be argued that the decreased body weight gain in the mice consequently inhibited adipogenesis in the early stage because of insufficient nutrient uptake. However, the unchanged expression levels of $\mathrm{C} / \mathrm{EBP} \beta$ and $\mathrm{C} / \mathrm{EBP} \delta$ (Figure S1c,d) suggested that early adipogenesis was not affected. Instead, a significant decrease in the PPAR $\gamma 2$ pathway indicated that DON exposure only inhibited the intermediate and late stages. In the mice exposed to DON, the mRNA and protein levels of the adipogenic marker genes C/ebp $\alpha$, Ppary2, Fasn, Acaca, Fabp4, and Cd36 were significantly decreased compared to those in the control group (Figure 6a-d). These results indicated that DON did not affect the early stage of adipogenesis but effectively inhibited the intermediate and late stages through the downregulation of adipogenic marker genes, both in vivo and in vitro. 
a

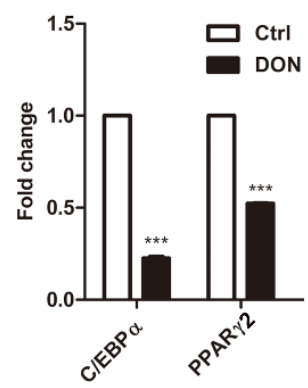

c

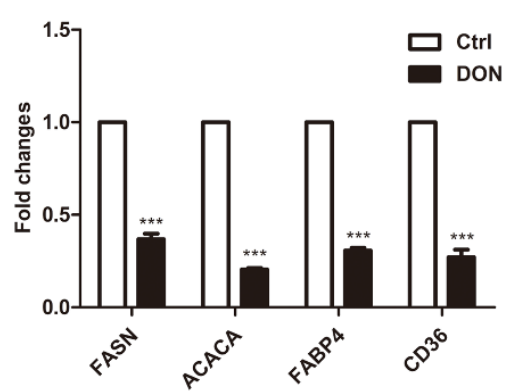

b

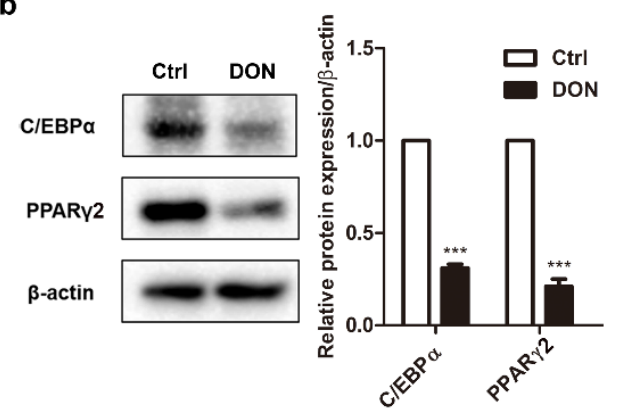

d

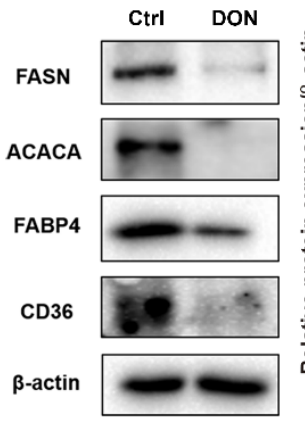

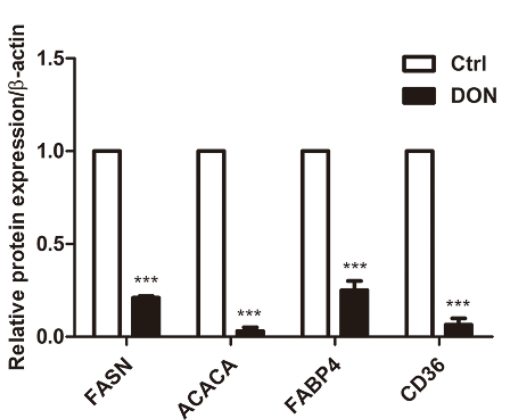

Figure 6. The effect of DON on the expression of adipogenic marker genes in mice $(n=5)$. $(\mathbf{a}, \mathbf{c})$ Clebp $\alpha$, Ppar 2 2, Fasn, Acaca, Fabp4, and Cd36 mRNA levels in mice. (b,d) C/EBP $\alpha$, PPAR $\gamma 2$, FASN, ACACA, FABP4, and CD36 protein levels in mice (left). Quantification of protein levels (right). The results are representative of three independent experiments, and statistical significance is indicated by $* * * p<0.001$.

2.7. DON Suppressed the Expression of PPAR $\gamma 2$ by Inhibiting the Enrichment of H3K4me2 and H3K4me3 in 3T3-L1 Cells

As mentioned above, DON inhibited adipogenesis via the inhibition of PPAR $\gamma 2$ expression. However, the mechanism behind this in 3T3-L1 cells remains to be elucidated. It is well recognized that DON activates mitogen activated protein kinases (MAPK) subfamily members [35-37]. We speculated that DON stimulated the phosphorylation of PPAR $\gamma 2$ by activating the MAPK pathways. Indeed, DON significantly upregulated p38 and JNK but not ERK (Figure S4a). However, the DON-induced activation of MAPK did not affect significantly the phosphorylation of PPAR $\gamma 2$ (Figure S4b), suggesting that DON regulated PPAR $\gamma 2$ in a MAPK-independent manner. To determine if the inhibitory effect of DON on Ppar 2 was related to transcription, we employed the dual luciferase assay to analyze the promoter activity of Ppar 2 in HEK293T cells. A $1.0 \mathrm{~kb}$ segment of Ppar 2 promoter DNA was cloned upstream of the firefly luciferase gene. The quantitative analysis referred to the promoter strength of PPAR 2 normalized by the luciferase activities relative to that obtained with the empty vector. However, the relative luciferase activity showed no significant change upon DON treatment in comparison with the control, which was treated with sterile water (DON solvent) (Figure S5). These results suggested that DON had no effect on the promoter activation of Ppar 2 at the transcriptional level.

Recent studies suggest that histone modifications play critical roles in regulating adipogenic gene expression and adipogenesis [38]. We investigated whether epigenetic changes mediated the DON-induced downregulation of PPAR $\gamma 2$. The demethylation and trimethylation levels of Histone 3 at lysine 4 were apparently decreased upon DON treatment, but there were no apparent changes in the acetylation of H3K9 and H3K27 (Figure 7a). ChIP-qPCR analysis further confirmed that the enrichment of H3K4me2 and H3K4me3 at the promoter of Ppar 2 decreased upon DON treatment (Figure $7 \mathrm{~b}$ ), while that of H3K9ac and H3K27ac was not significantly changed (Figure 7c). The enrichment of H3K4me2, H3K4me3, H3K9ac, and H3K27ac at the promoter of C/ebp $\alpha$ did not significantly change upon DON treatment (Figure 7d,e). These results suggested that DON suppressed the expression of 
PPAR $\gamma 2$ by reducing the enrichment of H3K $4 \mathrm{me} 2$ and H3K4me3 at the promoter of Ppar $\gamma 2$. Therefore, the decreased levels of H3K4me2 and H3K4me3 at the Ppar 2 promoter locus may account for the repression of adipogenesis upon DON treatment.

a

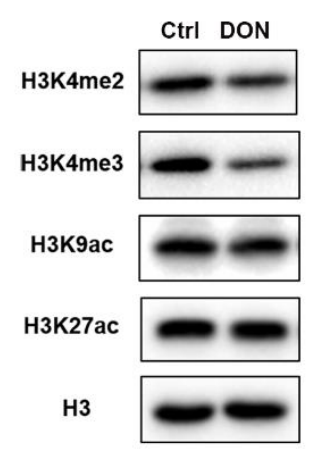

b

PPARY2

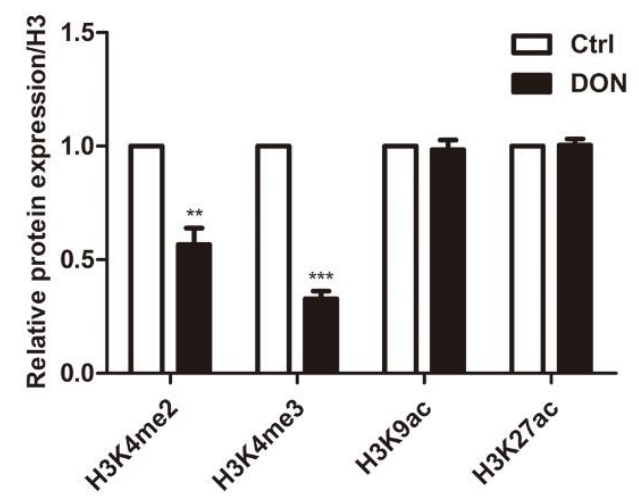

C

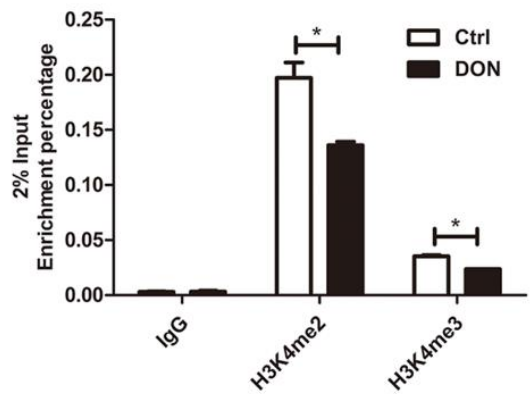

d C/EBPa

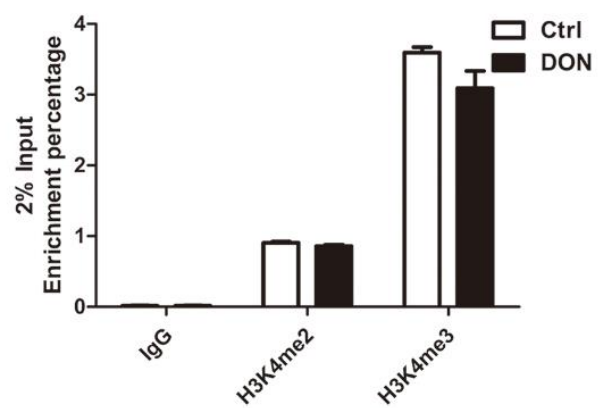

PPARY2

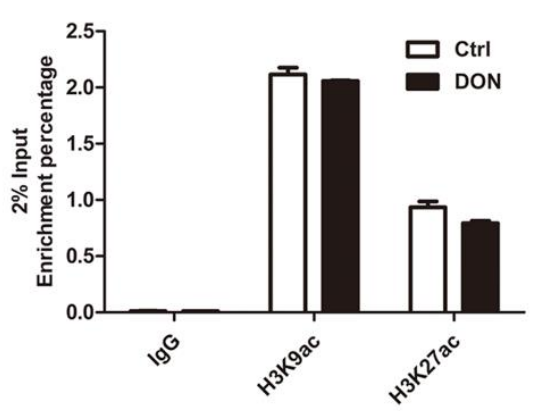

C/EBPa

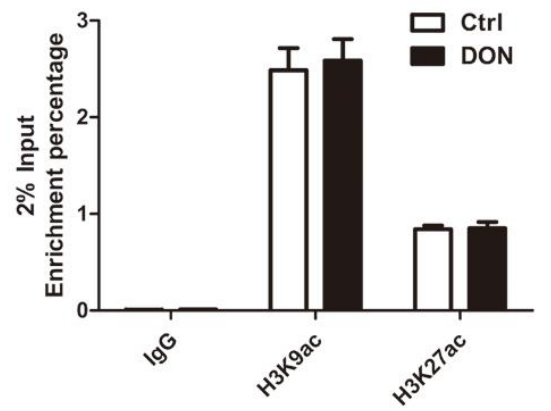

Figure 7. DON regulated the expression of PPAR $\gamma 2$ through H3K4me2 and H3K4me3. (a) 3T3-L1 cells were differentiated and treated with or without DON $(100 \mathrm{ng} / \mathrm{mL})$ for 7 days. The expression of H3K4me2, H3K4me3, H3K9ac, and H3K27ac was quantified by Western blotting in 3T3-L1 cells (left). Quantification of protein levels (right). (b) The 3T3-L1 cells were differentiated and treated with or without DON (100 ng/mL) for 7 days. The cells were prepared for ChIP assays using the indicated antibodies. The binding occupancy was monitored by qPCR using primer sets for the targeted promoter. ChIP assays of H3K4me2 and H3K4me3 on Ppary 2 promoter. (c) ChIP assays of H3K9ac and H3K27ac on Ppary 2 promoters. (d) ChIP assays of H3K4me2 and H3K4me3 on C/ebpo promoters. (e) ChIP assays of $\mathrm{H} 3 \mathrm{~K} 9 \mathrm{ac}$ and $\mathrm{H} 3 \mathrm{~K} 27 \mathrm{ac}$ on C/ebp $\alpha$ promoters. The data are expressed as the fold enrichment relative to that of $\operatorname{IgG}$ normalized to that of a nonbinding region. The results are representative of three independent experiments, and statistical significance is indicated by ${ }^{*} p<0.05,{ }^{* *} p<0.01,{ }^{* * *} p<0.001$. 


\section{Discussion}

DON-contaminated food (particularly wheat, maize, barley, and their byproducts) is harmful for animal and human health. DON causes ribosomal stress toxicity, oxidative stress, and immune disorders $[7,39,40]$. We confirmed that DON dramatically decreased lipid accumulation and TG levels in 3T3-L1 cells. Similar effects were also observed in vivo, where DON decreased the volume and sizes of eWAT and pWAT, and reduced TG content. Our current study suggested that the master regulator PPAR $\gamma 2$ was probably a novel DON target in the toxicosis of DON, similar to $\beta$-catenin that we previously identified [41]. More importantly, the interruption of the intermediate and late stages of adipogenesis by the low dose of DON might be one of the mechanisms behind the decreased weight gain in the animals fed DON-contaminated feedstuffs, in addition to feed refusal, loss of appetite, acute vomiting, and diarrhea.

Adipogenesis is a process for adipocyte differentiation and lipid accumulation [42,43]. Preadipocyte differentiation into mature adipocytes is a tightly controlled and stepwise process that involves the expression changes of serial adipogenic genes and expansion of intracellular lipid droplets. The sequential activations of adipocyte-related transcription factors govern the differentiation of preadipocytes into mature adipocytes [44]. Our results show that DON exposure suppressed the expression of PPAR $\gamma 2$ and further inhibited the expression of other adipogenic marker genes-Fasn, Aacac, Fabp4, and Cd36-which were required for adipogenesis in both cells and mice. In 3T3-L1 cells, DON globally decreased the di-/trimethylation level of H3K4 and, especially at the Ppar 2 promoter locus, suppressed the transcription of Ppar 2 , consequently inhibiting adipogenic marker expression during the intermediate and late stages of adipogenesis.

PPAR $\gamma 2$ is considered one of the most important regulators of adipogenesis [45], and a complicated mutual modulation occurs between PPAR $\gamma 2$ and $\mathrm{C} / \mathrm{EBP} \alpha$. They promote each other's expression and cooperate to activate the expressions of thousands of genes involved in late adipogenesis [14]. A recent study reported that another type $B$ trichothecene, fusarenon- $X$, is a stronger inducer of intestinal inflammation, and PPAR $\gamma$ is also downregulated after its administration [46]. In HCT-8 cells, DON may suppress PPAR $\gamma$ expression via CCAAT/enhancer-binding protein homologous protein (CHOP). The transcription level of $C H O P$ is enhanced by DON, and the high expression of $\mathrm{CHOP}$ further downregulates the expression of PPAR $\gamma$ [47]. All of these studies imply that type B trichothecenes negatively regulate PPAR $\gamma$. In our study, we also confirmed that DON downregulated the expression of Ppary 2 both in vitro and in vivo. DON also markedly decreased the expression of two rate-limiting enzymes in lipogenesis, FASN and ACACA, which are involved in de novo fatty acid synthesis [48]. The expression of FABP4 and CD36, two proteins involved in cytoplasmic fatty acid transport for metabolic processing or storage, was also decreased. Conclusively, DON inhibited the expression of PPAR $\gamma 2$ and, subsequently, C/EBP $\alpha$, reducing the expression of other adipogenic marker genes in adipocytes. Because the expression of FASN, ACACA, FABP4, and CD36 is known to be controlled by PPAR $\gamma$ [32,49-51], we reasoned that DON suppressed adipocyte differentiation by acting on the PPAR $\gamma 2$ pathway. PPAR $\gamma 2$ overexpression reversed the suppression by DON and induced lipid accumulation, consistent with a previous report [19]. RGZ treatment rescued the lipid accumulation in DON-treated 3T3-L1 cells but less so than PPAR $\gamma 2$ overexpression. This further confirmed that DON exposure decreased the protein level of PPAR $\gamma 2$. During the early stage of adipogenesis, C/EBP $\beta$ and $\mathrm{C} / \mathrm{EBP} \delta$ activate the expression of $\mathrm{C} / \mathrm{EBP} \alpha, \operatorname{PPAR} \gamma$, and probably other adipogenic genes [52]. Interestingly, DON did not affect the expression of $\mathrm{C} / \mathrm{EBP} \beta$ and $\mathrm{C} / \mathrm{EBP} \delta$, in vitro or in vivo. This suggests that DON possibly has no regulatory effect on the early stage of adipogenesis but regulates PPAR $\gamma 2$ expression in the intermediate and late stages of adipogenesis. More importantly, this indicates that lower nutrient uptake due to the feed refusal, vomiting, or diarrhea caused by DON exposure does not account for DON-induced adipogenesis suppression, otherwise the expression of C/EBP $\beta$ or C/EBP $\delta$ would also be changed $[53,54]$. Therefore, the interruption of adipogenesis independently of malnutrition resulting from feed refusal, vomiting, or diarrhea might explain the decrease of weight gain by DON exposure in animals. 
The molecular basis of the DON-induced effects on PPAR $\gamma 2$ remains unclear. The MAPK-mediated phosphorylation of PPAR $\gamma 2$ has been proven to inhibit PPAR $\gamma 2$ activity [55]. ERK phosphorylates PPAR $\gamma 2$, which results in the inactivation of PPAR $\gamma 2$ activity [56]. Several studies have already shown that DON activates MAPK subfamily members [35-37]. However, we found that DON regulated the expression of PPAR $\gamma 2$ in a MAPK-independent manner, because DON exposure did not change PPAR $\gamma 2$ phosphorylation. Consistently, our results showed that DON enhanced the phosphorylation of p38 and JNK but not ERK, which had been reported to function in PPAR $\gamma 2$ phosphorylation. The transcriptional control of PPAR $\gamma$ expression has been extensively studied. Nevertheless, the promoter activity of Ppar 2 shows no significant change upon DON treatment. Histone modifications play important roles in regulating the expression of adipogenic marker genes and adipogenesis [38]. Those resulting in transcriptional activation or repression are observed near the Ppar 2 promoter in adipocytes [24]. It has been reported that the enrichment of H3K9ac and H3K27ac in promoter regions is affected by DON administration [57]. Interestingly, we found that the inhibitory effect of DON on the expression of PPAR $\gamma 2$ was mediated by inhibiting H3K4me2 and H3K4me3 enrichment instead of that of H3K9ac and H3K27ac at the promoter of Ppar 2 in 3T3-L1 cells. More importantly, H3K4me2 and H3K4me3 were globally repressed in 3T3-L1 cells by DON administration, possibly based on cell tropism. Such changes in adipocytes warrant further study. H3K4me2 is typically found at the enhancer element, while H3K4me3 is observed at promoter regions. Di-/trimethylation is associated with the histone lysine (K)-specific methyltransferase 2C/2D (MLL3/MLL4) [58]. The histone H3K4 methyltransferase MLL4 enhances the expression of PPAR $\gamma 2$ [59]. The idea that MLL3/4 may be downregulated in the inhibitory effect of DON on PPAR $\gamma 2$ expression remains to be further addressed. In addition, PPAR $\gamma 2$ 's functions are also regulated by various post-translational modifications (PTMs) including SUMOylation, ubiquitination, acetylation, and O-GlcNAcylation, at numerous sites [60]. Further research is required to elucidate the mechanisms affecting the expression or activity of PPAR $\gamma 2$ in DON treatment.

Our study demonstrates that DON—a type B trichothecene-inhibits adipogenesis, a novel toxic effect, even at low doses. In particular, we show that the pivotal regulator PPAR $\gamma 2$ is targeted by DON, which inhibits its expression during the intermediate and late stages of adipogenesis. We proposed that the di-/trimethylation level of H3K4 mediates the DON-induced downregulation of PPAR $\gamma 2$. The inhibition of adipogenesis by DON may have consequences for animal health and highlights the potential risk of the long-term consumption of food contaminated by DON in animals and humans.

\section{Materials and Methods}

\subsection{Cell Culture}

3T3-L1 (ATCC CL-173) cells were purchased from American Type Culture Collection (ATCC, Manassas, VA, USA) and cultured in Dulbecco's modified Eagle's medium (Thermo Fisher, Waltham, MA, USA) supplemented with 10\% fetal bovine serum (Biological Industries, Kibbutz Beit Haemek, Israel) in a $37^{\circ} \mathrm{C}$ incubator containing a $5 \% \mathrm{CO}_{2}$ atmosphere. For adipocyte differentiation, 3T3-L1 preadipocytes were trypsinized and plated in a 12-well plate. Cells were cultured for an additional day after reaching confluency, and $10 \mathrm{mg} / \mathrm{mL}$ insulin (Sangon Biotech, Shanghai, China), $1 \mu \mathrm{M}$ dexamethasone (Sigma, St. Louis, MO, USA), and 0.5 mM 3-isobutyl-1-methylxanthine (Sangon Biotech, Shanghai, China) were added to the culture medium for 2 days. The medium was then replaced with the basic culture medium containing only $10 \mathrm{mg} / \mathrm{mL}$ insulin for another 2 days. From Days 4 to 7 , the cells were maintained in basic culture medium and were additionally administrated $100 \mathrm{ng} / \mathrm{mL}$ DON and $1 \mu \mathrm{M}$ rosiglitazone (RGZ) (MedChemExpress, Princeton, NJ, USA) from Days 0 to 7 during differentiation. The DON and RGZ were replenished every two days. 


\subsection{Construction of Plasmids, Adenovirus Transfection, and Luciferase Activity Detection}

Based on NCBI GenBank, we amplified the open reading frame (ORF) of mouse PPAR $\gamma 2$ (GenBank Accession Number: NC_000072.6) without a stop codon by PCR. cDNA from the reverse transcription of RNA from 3T3-L1 adipocytes was used as a template. The pSIN-cFlag-Pur vector was digested with the restriction enzyme SnaB I (NEB, Beijing, China). The expression vector pSIN-PPAR $\gamma 2$-cFlag-Pur-containing mouse PPAR $\gamma 2$ was constructed by subcloning the corresponding cDNA of PPAR $\gamma 2$ into N-terminal Flag-tagged pSIN-cFlag-Pur (Invitrogen, Rockville, MD, USA) using a ClonExpress II One-Step Cloning Kit (Vazyme, Nanjing, China) according to the manufacturer's instructions. Adenoviruses encoding PPAR $\gamma 2$ were generated by the transfection of the plasmids containing the expression vector of a PPAR $\gamma 2$ construct, psPAX2 (Invitrogen, Rockville, MD, USA), pMD2.G (Invitrogen, Rockville, MD, USA), and an empty vector (pSIN-cFlag-Pur) as the control. Finally, puromycin was used to select for the stably expressing cells.

According to NCBI GenBank, the $5^{\prime}$-flanking region from -1000 to -1 of the construct (the translational start site was designated +1 ) of mouse Ppar 2 was amplified by using mouse genomic DNA from 3T3-L1 cells by PCR. The Sac I (TaKara, Qingdao, China)- and Xho I (Takara, Qingdao, China)-digested PCR fragments were inserted upstream of pGL3-Basic (Promega Corp., Madison, WI, USA) to generate the luciferase reporter constructs. HEK293T cells were seeded into 24-well plates and cultured in DMEM until reaching $80 \%$ confluence. For the transfection reporter constructs of PPAR $\gamma 2$, $0.6 \mu \mathrm{g}$ of firefly luciferase reporter plasmids and $0.06 \mu \mathrm{g}$ of Renilla luciferase reporter plasmid (pRL-TK) (Promega Corp., Madison, WI, USA) were incubated with $1.5 \mu \mathrm{L}$ of Lipofectamine 3000 (Invitrogen, CA, USA). The transfected cells were incubated for $24 \mathrm{~h}$, and then, the transfected cells were treated with DON or sterile water for another $24 \mathrm{~h}$. The cells were lysed, and the luciferase reporter activity was measured with the dual luciferase reporter assay system (Promega Corp., Madison, WI, USA) according to the manufacturer's instructions. The strength of the promoter's transcription was represented by the relative luciferase activity, and the firefly luciferase activity in each construct was normalized to the Renilla luciferase activity as a transfection reference. All experiments were performed three times independently. The specific primer sets used for the construction of the expression vector are listed in Table S1.

\subsection{Cell Viability Assay}

3T3-L1 preadipocytes were grown in a 96-well plate at an initial density of $1.5 \times 10^{4} \mathrm{cells} / \mathrm{cm}^{2}$ in the presence of DON at different concentrations $(50,100,200,400$, or $800 \mathrm{ng} / \mathrm{mL}$ ) for 1, 2, 3, or $7 \mathrm{~d}$. Cell viability was determined using a Cell Counting Kit (CCK-8) (Ye Sen, Guangdong, China). The absorbance at $450 \mathrm{~nm}$ was measured with a spectrophotometer using SoftMax Pro 7.0 (Molecular Devices, Sunnyvale, CA, USA).

\subsection{Oil Red O Staining}

The mature adipocytes were grown on a coverslip and fixed with $10 \%$ formalin (Guangzhou Dingguo Biology, Guangdong, China) at room temperature for $1 \mathrm{~h}$. After fixation, the cells were washed once with $60 \%$ isopropyl alcohol (Sangon Biotech, Shanghai, China). Oil Red O solution (Sangon Biotech, Shanghai, China) was prepared according to the manufacturer's instructions and added to the plate for $1 \mathrm{~h}$. The coverslips were then visualized under a microscope. The cell culture plates were treated with isopropanol (Sangon Biotech, Shanghai, China), and lipid accumulation was determined according to absorbance at $510 \mathrm{~nm}$.

\subsection{TG Colorimetric Assay}

The mature adipocytes were washed with ice-cold PBS, collected in $200 \mu \mathrm{L}$ of cold sonication buffer ( $25 \mathrm{mM}$ Tris buffer containing $1 \mathrm{mM}$ EDTA, pH 7.4) using a cell scraper, and then sonicated. The supernatants were used to measure intracellular TG levels using a TG kit (Jiancheng Institute of 
Biotechnology, Nangjing, China), according to the manufacturer's instructions. Epididymal white adipose tissues (eWAT) and perirenal white adipose tissues (pWAT) were homogenized in ethanol solution $(9: 1 \mathrm{~V} / \mathrm{m})$ before centrifugation, and the supernatants were used to measure TG levels using a TG kit.

\subsection{Real-Time PCR ( $q P C R)$}

Total RNA was isolated from eWAT isolated adipocytes, liver, kidney, or 3T3-L1 adipocytes using TRIzol reagent (Thermo Fisher, Waltham, MA, USA) under RNase-free conditions. Reverse transcription and qPCR were performed in a simultaneous reaction using Hifair TM III One Step RT-qPCR Probe Kit (Ye Sen, Guangdong, China) according to the manufacturer's instructions. All RT-qPCR reactions were carried out in a 96-well plate format on a CFX Connect real time qPCR machine (Bio-Rad Laboratories, Hercules, CA, USA). The amplification protocol included an initial denaturation step of $10 \mathrm{~min}$ at $95^{\circ} \mathrm{C}$ followed by 40 cycles consisting of denaturation for $15 \mathrm{~s}$ at $95^{\circ} \mathrm{C}$, annealing for 1 min at $55^{\circ} \mathrm{C}$, and extension for $1 \mathrm{~min}$ at $72^{\circ} \mathrm{C}$, followed by melting curve analysis. Relative expression was normalized to $\beta$-actin using the $2^{-\Delta \Delta C t}$ method. The amplification of specific transcripts was confirmed by obtaining melting curves between 55 and $95^{\circ} \mathrm{C}$. The specific primer sets used for qPCR are listed in Table S2.

\subsection{Western Blotting}

Cells were lysed in NETN (20 mM Tris-HCl pH 8.0, $100 \mathrm{mM} \mathrm{NaCl}, 1 \mathrm{mM}$ EDTA, 0.5\% NP-40) supplemented with a protease inhibitor cocktail (Bimake, Houston, TX, USA). Protein concentrations were determined using a BCA Protein Assay Kit (Guangzhou Dingguo Biology, Guangdong, China). All protein samples were separated by sodium dodecylsulphate-polyacrylamide gel electrophoresis (Bio-Rad Laboratories, Hercules, CA, USA) and transferred to PVDF membranes (Merck Millipore, Burlington, MA, USA), which were blocked with 5\% skim milk (Guangzhou Dingguo Biology, Guangdong, China) and hybridized with primary antibodies. Horseradish peroxidase-conjugated donkey anti-goat IgG, goat anti-rabbit IgG, and rabbit anti-mouse IgG (Cell Signaling Technology, Danvers, MA, USA) were used as secondary antibodies. Signals were detected by using the ChemiDoc MP system (Bio-Rad Laboratories, Hercules, CA, USA) with the BeyoECL Star (Beyotime, Beijing, China) or the Efficient Chemiluminescence Kit (Genview, Guangdong, China). The bands were quantified using Image Lab 4.1 (Bio-Rad Laboratories, Hercules, CA, USA).

Anti-PPAR $\gamma$ (sc-7273, Santa Cruz Biotechnology, Dallas, TX, USA), anti-C/EBP $\alpha$ (sc-9315X, Santa Cruz Biotechnology, Dallas, TX, USA), anti-C/EBP $\beta$ (D155298, Sangon Biotech, Shanghai,

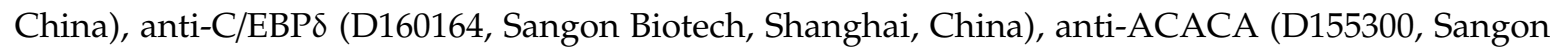
Biotech, Shanghai, China), anti-FASN (D262701, Sangon Biotech, Shanghai, China), anti-FABP4 (D120618, Sangon Biotech, Shanghai, China), anti-CD36 (D161529, Sangon Biotech, Shanghai, China), anti-p-PPAR $\gamma$ (bs-3737R Bioss, Beijing, China), anti-H3K4me2 (9725S, Cell Signaling Technology, Danvers, MA, USA), anti-H3K4me3 (9751S, Cell Signaling Technology, Danvers, MA, USA), anti-H3K9ac (9649S, Cell Signaling Technology, Danvers, MA, USA), anti-H3K27ac (8173S, Cell Signaling Technology, Danvers, MA, USA), anti-H3 (4620S, Cell Signaling Technology, Danvers, MA, USA), anti-ERK (AF1051, Beyotime Biotechnology, Shanghai, China), anti-p-ERK (AF1891, Beyotime Biotechnology, Shanghai, China), anti-JNK (AF1048, Beyotime Biotechnology, Shanghai, China), anti-p-JNK (AF1762, Beyotime Biotechnology, Shanghai, China), anti-p38 (AF7668, Beyotime Biotechnology, Shanghai, China), anti-p-p38 (AM063, Beyotime Biotechnology, Shanghai, China), and anti- $\beta$-actin (R4967S, Cell Signaling Technology, Danvers, MA, USA) antibodies were used for Western blot analysis.

\subsection{Chromatin Immunoprecipitation (ChIP) Assays}

Chromatin immunoprecipitation assays were performed using the ChIP Assay Kit (Millipore, Billerica, Massachusetts, USA). In brief, 3T3-L1 cells were fixed with 1\% formaldehyde for $10 \mathrm{~min}$ at 37 ${ }^{\circ} \mathrm{C}$ to form DNA-protein crosslinks and quenched with $0.125 \mathrm{M}$ glycine. Chromatin was isolated by 
the addition of lysis buffer. Each sample was sonicated on ice and then incubated with antibody at 4 ${ }^{\circ} \mathrm{C}$ overnight. The PCR quantitation of precipitated genomic DNA relative to input was performed in triplicate using a qPCR Probe Kit (Ye Sen, Guangdong, China) according to the manufacturer's instructions. The sequences of the primers are listed in Table S3. The antibodies used were as follows: anti-IgG (R3900S, Cell Signaling Technology, Danvers, MA, USA), anti-H3K4me2, anti-H3K4me3, anti-H3K9ac, and anti-H3K27ac.

\subsection{Experimental Animals}

All experimental procedures were performed in conformance with the guidelines on animal experiments provided by the Institutional Care Committee of South China Agricultural University (Permit No.01952236, Date: 25 June 2019) (Guangzhou, Guangdong, China). Five-week-old specific-pathogen-free (SPF) male BALB/c mice were purchased from the Guangdong Medical Laboratory Animal Center (GDMLAC, Foshan, China). All the animals were fed with a standard diet (AIN-93M). The mice were housed in the animal facility under standard conditions (12/12 h light-dark cycle, $50 \pm 15 \%$ humidity, $22 \pm 2{ }^{\circ} \mathrm{C}$ temperature) for one week and then randomly assigned to two groups based on intragastric administration ( $n=5 /$ group): control group and DON (Sigma, St. Louis, MO, USA) group. The mice in the control group were administered $100 \mu \mathrm{L}$ of sterile water. The mice in the DON group were administered DON at a dosage of $3.0 \mathrm{mg} / \mathrm{kg}$ body weight $(100 \mu \mathrm{L})$ as in a previous study [61]. All the administrations were performed daily by gavage for four weeks. Body weight was recorded once a week. At the end of the administration period, the mice were sacrificed by cervical dislocation. The WAT, liver, and kidney were separated and weighed from each mouse, immediately frozen in liquid nitrogen, and stored at $-80^{\circ} \mathrm{C}$ until use.

\subsection{Histological Analysis}

For histological analysis, the adipocyte tissue was subsequently fixed in $4 \% w / v$ paraformaldehyde/PBS and embedded in paraffin, as previously described [62]. Hematoxylin and eosin (HE) staining was performed and visualized using a microscope. The size of the adipose tissue was measured using the Image J software with Adipocytes Tools plugins.

\subsection{Statistical Analysis}

For each experiment, three replicates were performed. Statistical differences between experimental groups were evaluated by one-way analysis of variance (ANOVA) with the least significant difference (LSD) test. All statistical analyses were performed using SPSS 20.0 (IBM, New York, USA). Statistical significance was defined by ${ }^{*} p<0.05,{ }^{* *} p<0.01{ }^{* * *} p<0.001$.

Supplementary Materials: Supplementary materials can be found at http://www.mdpi.com/1422-0067/21/17/ 6300/s1. Figure S1: The effect of DON on the expressions of C/EBP $\beta$ and C/EBPS, both in vitro and in vivo. Figure S2: PPAR $\gamma 2$ overexpression in 3T3-L1 cells. Expression vector containing mouse PPAR $\gamma 2$ was constructed by subcloning the corresponding cDNA into N-terminal Flag-tagged pSIN-cFlag-Pur. Figure S3: The effect of DON on the change in body weight, liver function, and renal function. Figure S4. The effect of DON on the expression of MAPK and p-PPAR $\gamma 2$ in 3T3-L1 cells. Figure S5: Analysis of the Ppar 2 promoter in HEK293T cells treated with DON. Table S1: Primers for construction of expression vector. Table S2: Primers for quantitative real-time PCR. Table S3: Primers for ChIP analysis.

Author Contributions: Conceptualization, Y.Z., J.W. and Y.D.; Methodology, Y.Z., S.T., R.L. and D.L.; Formal analysis, Y.Z., T.Z., X.C. and J.Z.; Writing - Original Draft Preparation, Y.Z., S.T. and J.W; Writing - Review \& Editing, Y.Z., J.W., and Y.D.; Funding acquisition, J.W., and Y.D. All authors have read and agreed to the published version of the manuscript.

Funding: This research was funded by the Department of Education of Guangdong Province (grants number 2018KZDXM015, 2017KCXTD001), the Science and Technology Program of Guangzhou (Grant number 201804020067), the Natural Science Foundation of Guangdong Province (Grant number 2015A030312005), and the Joint Fund of National Natural Science Foundation of China and Guangdong Province (Grant number U1901207). 
Conflicts of Interest: The authors declare no conflict of interest. The funders had no role in the design of the study; in the collection, analyses, or interpretation of data; in the writing of the manuscript, or in the decision to publish the results.

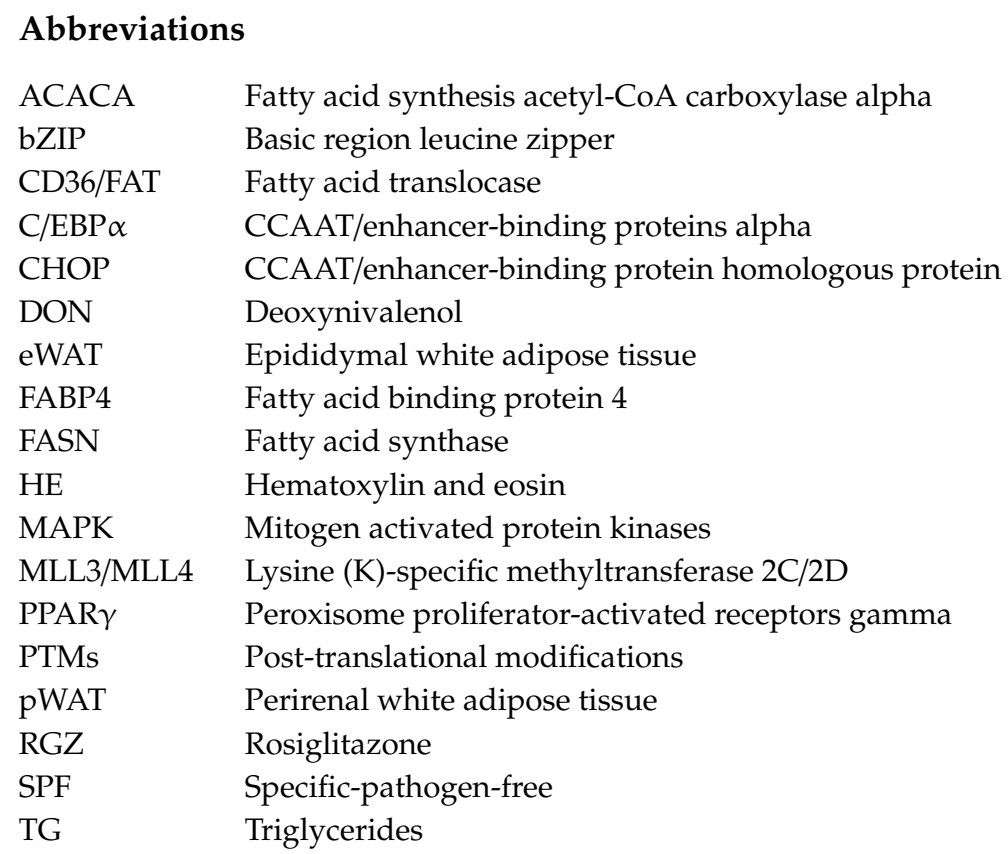

\section{References}

1. Wang, Z.; Wu, Q.; Kuca, K.; Dohnal, V.; Tian, Z. Deoxynivalenol: Signaling pathways and human exposure risk assessment-An update. Arch. Toxicol. 2014, 88, 1915-1928. [CrossRef]

2. Wu, Q.; Lohrey, L.; Cramer, B.; Yuan, Z.; Humpf, H.U. Impact of physicochemical parameters on the decomposition of deoxynivalenol during extrusion cooking of wheat grits. J. Agric. Food Chem. 2011, 59, 12480-12485. [CrossRef] [PubMed]

3. Vesonder, R.F.; Ciegler, A.; Jensen, A.H. Isolation of the emetic principle from Fusarium-infected corn. Appl. Microbiol. 1973, 26, 1008-1010. [CrossRef] [PubMed]

4. Pestka, J.J. Deoxynivalenol-induced proinflammatory gene expression: Mechanisms and pathological sequelae. Toxins 2010, 2, 1300-1317. [CrossRef] [PubMed]

5. Pestka, J.J. Deoxynivalenol: Mechanisms of action, human exposure, and toxicological relevance. Arch. Toxicol. 2010, 84, 663-679. [CrossRef]

6. Frankic, T.; Pajk, T.; Rezar, V.; Levart, A.; Salobir, J. The role of dietary nucleotides in reduction of DNA damage induced by T-2 toxin and deoxynivalenol in chicken leukocytes. Food Chem. Toxicol. 2006, 44, 1838-1844. [CrossRef]

7. Payros, D.; Alassane-Kpembi, I.; Pierron, A.; Loiseau, N.; Pinton, P.; Oswald, I.P. Toxicology of deoxynivalenol and its acetylated and modified forms. Arch. Toxicol. 2016, 90, 2931-2957. [CrossRef]

8. Pierron, A.; Mimoun, S.; Murate, L.S.; Loiseau, N.; Lippi, Y.; Bracarense, A.P.; Liaubet, L.; Schatzmayr, G.; Berthiller, F.; Moll, W.D.; et al. Intestinal toxicity of the masked mycotoxin deoxynivalenol-3-beta-D-glucoside. Arch. Toxicol. 2016, 90, 2037-2046. [CrossRef]

9. Lowell, B.B. PPARgamma: An essential regulator of adipogenesis and modulator of fat cell function. Cell 1999, 99, 239-242. [CrossRef]

10. Lehrke, M.; Lazar, M.A. The many faces of PPARgamma. Cell 2005, 123, 993-999. [CrossRef]

11. Moseti, D.; Regassa, A.; Kim, W.K. Molecular Regulation of Adipogenesis and Potential Anti-Adipogenic Bioactive Molecules. Int. J. Mol. Sci. 2016, 17, 124. [CrossRef] [PubMed]

12. Song, Y.; Lee, S.J.; Jang, S.H.; Kim, T.H.; Kim, H.D.; Kim, S.W.; Won, C.K.; Cho, J.H. Annual Wormwood Leaf Inhibits the Adipogenesis of 3T3-L1 and Obesity in High-Fat Diet-Induced Obese Rats. Nutrients 2017, 9, 554. [CrossRef] [PubMed] 
13. Cao, Z.; Umek, R.M.; McKnight, S.L. Regulated expression of three C/EBP isoforms during adipose conversion of 3T3-L1 cells. Genes Dev. 1991, 5, 1538-1552. [CrossRef] [PubMed]

14. Farmer, S.R. Transcriptional control of adipocyte formation. Cell Metab. 2006, 4, 263-273. [CrossRef] [PubMed]

15. Rosen, E.D.; Spiegelman, B.M. Adipocytes as regulators of energy balance and glucose homeostasis. Nature 2006, 444, 847-853. [CrossRef] [PubMed]

16. Rosen, E.D.; Walkey, C.J.; Puigserver, P.; Spiegelman, B.M. Transcriptional regulation of adipogenesis. Genes Dev. 2000, 14, 1293-1307. [PubMed]

17. Landschulz, W.H.; Johnson, P.F.; Adashi, E.Y.; Graves, B.J.; McKnight, S.L. Isolation of a recombinant copy of the gene encoding C/EBP. Genes Dev. 1988, 2, 786-800. [CrossRef]

18. Koschmieder, S.; Halmos, B.; Levantini, E.; Tenen, D.G. Dysregulation of the C/EBP $\alpha$ differentiation pathway in human cancer. J. Clin. Oncol. 2009, 27, 619-628. [CrossRef]

19. Tontonoz, P.; Hu, E.; Spiegelman, B.M. Stimulation of adipogenesis in fibroblasts by PPAR gamma 2, a lipid-activated transcription factor. Cell 1994, 79, 1147-1156. [CrossRef]

20. Ren, D.; Collingwood, T.N.; Rebar, E.J.; Wolffe, A.P.; Camp, H.S.; Ren, D.; Collingwood, T.N.; Rebar, E.J.; Wolffe, A.P.; Camp, H.S. PPAR $\gamma$ knockdown by engineered transcription factors: Exogenous PPAR $\gamma 2$ but not PPAR $\gamma 1$ reactivates adipogenesis. Genes Dev. 2002, 16, 27-32. [CrossRef]

21. Rosen, E.D.; Spiegelman, B.M. PPARgamma: A nuclear regulator of metabolism, differentiation, and cell growth. J. Biol. Chem. 2001, 276, 37731-37734. [CrossRef] [PubMed]

22. Jin, Q.; Wang, C.; Kuang, X.; Feng, X.; Sartorelli, V.; Ying, H.; Ge, K.; Dent, S.Y. Gcn5 and PCAF regulate PPARgamma and Prdm16 expression to facilitate brown adipogenesis. Mol. Cell. Biol. 2014, 34, 3746-3753. [CrossRef] [PubMed]

23. Seale, P.; Bjork, B.; Yang, W.; Kajimura, S.; Chin, S.; Kuang, S.; Scime, A.; Devarakonda, S.; Conroe, H.M.; Erdjument-Bromage, H.; et al. PRDM16 controls a brown fat/skeletal muscle switch. Nature 2008, 454, 961-967. [CrossRef] [PubMed]

24. Mikkelsen, T.S.; Xu, Z.; Zhang, X.; Wang, L.; Gimble, J.M.; Lander, E.S.; Rosen, E.D. Comparative epigenomic analysis of murine and human adipogenesis. Cell 2010, 143, 156-169. [CrossRef] [PubMed]

25. Ali, D.; Hamam, R.; Alfayez, M.; Kassem, M.; Aldahmash, A.; Alajez, N.M. Epigenetic Library Screen Identifies Abexinostat as Novel Regulator of Adipocytic and Osteoblastic Differentiation of Human Skeletal (Mesenchymal) Stem Cells. Stem Cells Transl. Med. 2016, 5, 1036-1047. [CrossRef] [PubMed]

26. Nolte, R.T.; Wisely, G.B.; Westin, S.; Cobb, J.E.; Lambert, M.H.; Kurokawa, R.; Rosenfeld, M.G.; Willson, T.M.; Glass, C.K.; Milburn, M.V. Ligand binding and co-activator assembly of the peroxisome proliferator-activated receptor-gamma. Nature 1998, 395, 137-143. [CrossRef] [PubMed]

27. Hadrich, F.; Sayadi, S. Apigetrin inhibits adipogenesis in 3T3-L1 cells by downregulating PPAR $\gamma$ and CEBP- $\alpha$. Lipids Health Dis. 2018, 17, 95. [CrossRef]

28. Levert, K.L.; Waldrop, G.L.; Stephens, J.M. A biotin analog inhibits acetyl-CoA carboxylase activity and adipogenesis. J. Biol. Chem. 2002, 277, 16347-16350. [CrossRef]

29. Kralisch, S.; Fasshauer, M. Adipocyte fatty acid binding protein: A novel adipokine involved in the pathogenesis of metabolic and vascular disease? Diabetologia 2013, 56, 10-21. [CrossRef]

30. Terra, X.; Quintero, Y.; Auguet, T.; Porras, J.A.; Hernandez, M.; Sabench, F.; Aguilar, C.; Luna, A.M.; Del Castillo, D.; Richart, C. FABP 4 is associated with inflammatory markers and metabolic syndrome in morbidly obese women. Eur. J. Endocrinol. 2011, 164, 539-547. [CrossRef]

31. Wolf Greenstein, A.; Majumdar, N.; Yang, P.; Subbaiah, P.V.; Kineman, R.D.; Cordoba-Chacon, J. Hepatocyte-specific, PPARgamma-regulated mechanisms to promote steatosis in adult mice. J. Endocrinol. 2017, 232, 107-121. [CrossRef] [PubMed]

32. Zhong, Q.; Zhao, S.; Yu, B.; Wang, X.; Matyal, R.; Li, Y.; Jiang, Z. High-density lipoprotein increases the uptake of oxidized low density lipoprotein via PPAR $\gamma / \mathrm{CD} 36$ pathway in inflammatory adipocytes. Int. J. Biol. Sci. 2015, 11, 256-265. [CrossRef] [PubMed]

33. Green, H.; Meuth, M. An established pre-adipose cell line and its differentiation in culture. Cell 1974, 3, 127-133. [CrossRef]

34. Park, B.O.; Ahrends, R.; Teruel, M.N. Consecutive positive feedback loops create a bistable switch that controls preadipocyte-to-adipocyte conversion. Cell Rep. 2012, 2, 976-990. [CrossRef] 
35. Wang, M.; Wang, J.J.; Li, J.; Park, K.; Qian, X.; Ma, J.X.; Zhang, S.X. Pigment epithelium-derived factor suppresses adipogenesis via inhibition of the MAPK/ERK pathway in 3T3-L1 preadipocytes. Am. J. Physiol. Endocrinol. Metab. 2009, 297, E1378-E1387. [CrossRef]

36. Li, X.; Mu, P.; Qiao, H.; Wen, J.; Deng, Y. JNK-AKT-NF-kappaB controls P-glycoprotein expression to attenuate the cytotoxicity of deoxynivalenol in mammalian cells. Biochem. Pharmacol. 2018, 156, 120-134. [CrossRef] [PubMed]

37. Zhou, H.R.; Islam, Z.; Pestka, J.J. Rapid, sequential activation of mitogen-activated protein kinases and transcription factors precedes proinflammatory cytokine mRNA expression in spleens of mice exposed to the trichothecene vomitoxin. Toxicol. Sci. 2003, 72, 130-142. [CrossRef] [PubMed]

38. Wang, L.; Xu, S.; Lee, J.E.; Baldridge, A.; Grullon, S.; Peng, W.; Ge, K. Histone H3K9 methyltransferase G9a represses PPAR $\gamma$ expression and adipogenesis. Embo. J. 2013, 32, 45-59. [CrossRef] [PubMed]

39. Li, M.; Pestka, J.J. Comparative induction of $28 \mathrm{~S}$ ribosomal RNA cleavage by ricin and the trichothecenes deoxynivalenol and T-2 toxin in the macrophage. Toxicol. Sci. 2008, 105, 67-78. [CrossRef]

40. Mishra, S.; Dwivedi, P.D.; Pandey, H.P.; Das, M. Role of oxidative stress in Deoxynivalenol induced toxicity. Food Chem. Toxicol. 2014, 72, 20-29. [CrossRef]

41. Tang, S.; Chen, S.; Huang, B.; Jiang, J.; Wen, J.; Deng, Y. Deoxynivalenol induces inhibition of cell proliferation via the Wnt/ $\beta$-catenin signaling pathway. Biochem. Pharmacol. 2019, 166, 12-22. [CrossRef] [PubMed]

42. Shan, T.; Liu, J.; Wu, W.; Xu, Z.; Wang, Y. Roles of Notch Signaling in Adipocyte Progenitor Cells and Mature Adipocytes. J. Cell. Physiol. 2017, 232, 1258-1261. [CrossRef] [PubMed]

43. Seo, J.B.; Moon, H.M.; Kim, W.S.; Lee, Y.S.; Jeong, H.W.; Yoo, E.J.; Ham, J.; Kang, H.; Park, M.G.; Steffensen, K.R.; et al. Activated liver $\mathrm{X}$ receptors stimulate adipocyte differentiation through induction of peroxisome proliferator-activated receptor $\gamma$ expression. Mol. Cell. Biol. 2004, 24, 3430-3444. [CrossRef] [PubMed]

44. Ali, A.T.; Hochfeld, W.E.; Myburgh, R.; Pepper, M.S. Adipocyte and adipogenesis. Eur. J. Cell. Biol. 2013, 92, 229-236. [CrossRef]

45. Rosen, E.D.; Hsu, C.H.; Wang, X.; Sakai, S.; Freeman, M.W.; Gonzalez, F.J.; Spiegelman, B.M. C/EBP $\alpha$ induces adipogenesis through PPAR $\gamma$ : A unified pathway. Genes Dev. 2002, 16, 22-26. [CrossRef]

46. Alassane-Kpembi, I.; Gerez, J.R.; Cossalter, A.M.; Neves, M.; Laffitte, J.; Naylies, C.; Lippi, Y.; Kolf-Clauw, M.; Bracarense, A.P.L.; Pinton, P.; et al. Intestinal toxicity of the type B trichothecene mycotoxin fusarenon-X: Whole transcriptome profiling reveals new signaling pathways. Sci. Rep. 2017, 7, 7530. [CrossRef]

47. Park, S.H.; Choi, H.J.; Yang, H.; Do, K.H.; Kim, J.; Moon, Y. Repression of peroxisome proliferator-activated receptor $\gamma$ by mucosal ribotoxic insult-activated CCAAT/enhancer-binding protein homologous protein. J. Immunol. 2010, 185, 5522-5530. [CrossRef]

48. Mashima, T.; Seimiya, H.; Tsuruo, T. De novo fatty-acid synthesis and related pathways as molecular targets for cancer therapy. Br. J. Cancer 2009, 100, 1369-1372. [CrossRef]

49. Jang, M.K.; Yun, Y.R.; Kim, J.H.; Park, M.H.; Jung, M.H. Gomisin N inhibits adipogenesis and prevents high-fat diet-induced obesity. Sci. Rep. 2017, 7, 40345. [CrossRef]

50. Lazra, Y.; Falach, A.; Frenkel, L.; Rozenberg, K.; Sampson, S.; Rosenzweig, T. Autocrine/paracrine function of globular adiponectin: Inhibition of lipid metabolism and inflammatory response in 3T3-L1 adipocytes. J. Cell. Biochem. 2015, 116, 754-766. [CrossRef]

51. Sugii, S.; Evans, R.M. Epigenetic codes of PPAR $\gamma$ in metabolic disease. FEBS Lett. 2011, 585, $2121-2128$. [CrossRef] [PubMed]

52. Noh, J.R.; Kim, Y.H.; Hwang, J.H.; Gang, G.T.; Yeo, S.H.; Kim, K.S.; Oh, W.K.; Ly, S.Y.; Lee, I.K.; Lee, C.H. Scoparone inhibits adipocyte differentiation through down-regulation of peroxisome proliferators-activated receptor $\gamma$ in 3T3-L1 preadipocytes. Food Chem. 2013, 141, 723-730. [CrossRef] [PubMed]

53. Ogawa, A.; Tsujinaka, T.; Yano, M.; Morita, S.; Taniguchi, M.; Kaneko, K.; Doki, Y.; Shiozaki, H.; Monden, M. Changes of liver-enriched nuclear transcription factors for albumin gene in starvation in rats. Nutrition 1999, 15, 213-216. [CrossRef]

54. Chapin, R.B.; Brady, P.S.; Barke, R.A.; Brady, L.J. Hepatic CCAAT/enhancer binding protein (C/EBP- $\alpha$ and C/EBP- $\beta$ ) expression changes with riboflavin deficiency, diet restriction and starvation in rats. J. Nutr. 1994, 124, 2365-2375. [CrossRef] [PubMed]

55. Floyd, Z.E.; Stephens, J.M. Controlling a master switch of adipocyte development and insulin sensitivity: Covalent modifications of PPAR $\gamma$. Biochim. Biophys. Acta 2012, 1822, 1090-1095. [CrossRef] 
56. Baek, S.J.; Wilson, L.C.; His, L.C.; Eling, T.E. Troglitazone, a Peroxisome Proliferator-activated Receptor $\gamma$ (PPAR $\gamma$ ) Ligand, Selectively Induces the Early Growth Response-1 Gene Independently of PPAR $\gamma$ : A novel mechanism for its anti-tumorigenic activity. J. Biol. Chem. 2003, 278, 5845-5853. [CrossRef]

57. Yuan, L.; Mu, P.; Huang, B.; Li, H.; Mu, H.; Deng, Y. EGR1 is essential for deoxynivalenol-induced G2/M cell cycle arrest in HepG2 cells via the ATF3DeltaZip2a/2b-EGR1-p21 pathway. Toxicol. Lett. 2018, 299, 95-103. [CrossRef]

58. Jozwik, K.M.; Chernukhin, I.; Serandour, A.A.; Nagarajan, S.; Carroll, J.S. FOXA1 Directs H3K4 Monomethylation at Enhancers via Recruitment of the Methyltransferase MLL3. Cell Rep. 2016, 17, 2715-2723. [CrossRef]

59. Jang, M.K.; Kim, J.H.; Jung, M.H. Histone H3K9 demethylase JMJD2B activates adipogenesis by regulating H3K9 methylation on PPAR $\gamma$ and C/EBP $\alpha$ during adipogenesis. PLoS ONE 2017, 12, e0168185. [CrossRef]

60. Reinhard, B.; Feng, X. Functional Regulation of PPARs through Post-Translational Modifications. Int. J. Mol. Sci. 2018, 19, 1738-1754.

61. Grenier, B.; Applegate, T.J. Modulation of intestinal functions following mycotoxin ingestion: Meta-analysis of published experiments in animals. Toxins 2013, 5, 396-430. [CrossRef] [PubMed]

62. Huang, W.C.; Fang, L.W.; Liou, C.J. Phloretin Attenuates Allergic Airway Inflammation and Oxidative Stress in Asthmatic Mice. Front. Immunol. 2017, 8, 134. [CrossRef] [PubMed]

(C) 2020 by the authors. Licensee MDPI, Basel, Switzerland. This article is an open access article distributed under the terms and conditions of the Creative Commons Attribution (CC BY) license (http://creativecommons.org/licenses/by/4.0/). 